\title{
Successful sacral nerve modulation despite migration of tined lead
}

\author{
Stefanie Dekkers ${ }^{* 1}$, Roderick F Schmitz ${ }^{1}$, Johannes TM van der Heyden ${ }^{2}$, Coen IM Baeten ${ }^{1}$ \\ ${ }^{1}$ Surgery Department, Groene Hart Hospital, Gouda, Netherlands \\ ${ }^{2}$ Department of Internal Medicine, Groene Hart Hospital, Gouda, Netherlands
}

Received: February 4, 2016

Accepted: March 13, 2016

Online Published: April 5, 2016

DOI: $10.5430 /$ css.v2n2p54

URL: http://dx.doi.org/10.5430/css.v2n2p54

\begin{abstract}
Background: Sacral nerve modulation (SNM) is a minimally invasive treatment for chronic constipation or incontinence when conservative treatment is insufficient to provide relieve of symptoms.

Case description: A 74-year-old patient with an implanted sacral nerve lead is presented in this case report with a dislodged lead without an adverse change in her incontinence treatment. This phenomenon has never been described before and raises the debate on sacral lead positioning in sacral nerve stimulation.

Discussion: There are a lot of conflicting data regarding ideal lead positioning, such as S3 versus S2 or S4 implantation. The lead position in our case doesn't correspond to previously described locations and pathways which corroborate the legitimacy of new developments in this area such as percutaneous tibial nerve stimulation, transcutaneous tibial nerve stimulation and transcutaneous abdominal electrical stimulation (TEN).

Conclusions: The implantation of SNM seems standardized but leaves voids in the technique where further research is needed to refine it.
\end{abstract}

Key Words: Sacral nerve modulation, Lead migration, Incontinence

\section{INTRODUCTION}

Sacral nerve modulation (SNM) is a relatively new and upcoming treatment when applied in chronic constipation or faecal incontinence cases. After the failure of conservative treatment (biofeedback training and bulk forming agents) and when anal sphincters are not amenable to repair or after unsuccessful surgery, surgical options are limited and often very invasive. It is in that context that SNM has been suggested to provide relieve and in so doing avoid a colostomy. Several retrospective trials and 3 prospective crossover trials have proven the beneficial effect of this technique in the treatment of faecal incontinence with an overall success rate of $65 \%-80 \%$ among these patients. ${ }^{[1-3]}$ The main advantage of this new technique is the possibility of reliably testing its effectiveness before carrying out the definitive procedure. ${ }^{[4]}$

In this article, a case is described of a 74-year-old patient who had a sacral lead implanted in 2002 in another hospital. The patient presented with a dislodged lead after falling down a flight of stairs, causing painful sensations in the left leg without a decrease in the effectiveness of the sacral neuromodulation. This phenomenon has never been described before and raises the debate on sacral lead positioning in sacral nerve stimulation.

\footnotetext{
${ }^{*}$ Correspondence: Stefanie Dekkers; Email: dekkersstefanie@ hotmail.com; Address: Surgery department, Groene Hart Hospital, Gouda, Netherlands.
} 


\section{Case presentation}

Patient G, a 74-year-old female, suffered from incontinence several years after the uncomplicated birth of her only child and undergoing a hysterectomy in 1972. in order to reduce the discomfort, the patient had an anal repair in 1992 with average success. Due to an increase in symptoms despite this previous surgery, the patient had a sacral nerve stimulator implanted in 2002. it was revised in 2003 with adequate relieve of her incontinence. The patient only lost some stool when exercising intensely with a maximum of twice a month.

The patient came to us out of concern for the position of a sacral nerve lead after a fall from a flight of stairs some time previously, leaving her bruised at the back, the left buttock and the left leg. Since then, the patient felt a painful sensation in the left leg whenever she turned the stimulator on. The pain subsided when the patient turned the stimulator off, all the while experiencing no change in the effects of her incontinence treatment. the patient also believed that the stimulator had shifted.

Upon examining the patient, the stimulator location was sensitive to touch. the patient also had a small swelling diagnosed at a previous consultation as some granulation tissue just medial of the stimulator, that leaked some serous fluid from time to time. Rectal exam revealed no abnormalities. A technician was asked to evaluate the stimulator and found no malfunction.

\subsection{Investigations}

An $X$-ray was made to evaluate the position of the stimulator as well as the lead. It showed an intact lead that had shifted from the correct position in the third sacral foramen to a more posterior location. (see Figure 1A and 1B)

\subsection{Treatment}

At first it was decided to turn off the stimulator completely with the idea that this would treat the painful sensation to the left leg. It was also hypothesised that it would not cause a relapse of symptoms with regard to her incontinence problems since the lengthy stimulation by the device might have caused a change in sensation at the level of the rectum, with better continence as a result.

\subsection{Outcome and follow-up}

At the next follow-up visit a couple of weeks later the patient complained of losing stool almost daily, proving the functionality of the stimulation despite its dislocated position. the patient was then booked for surgery. Under local anaesthesia a new temporary lead was positioned in the left fourth sacral foramen. When tested the new lead triggered a good sensory response at the anus prompting the switch for a permanent Published by Sciedu Press lead. The permanent lead was tunnelled underneath the skin and connected to the old pacemaker in the left buttock. An attempt was made to remove the old lead in the right sacral foramen but the lead broke and the distal end was left in place. After surgery the patient had regained good control of her bowel movements. the patient experienced no more episodes of incontinence. And although the painful sensation in her left leg improved it still persisted in an uncomfortable degree. After ruling out stimulator or lead infection, a neurologist consult identified arthrosis of the L4-L5 joint as a possible explanation for the patients' symptoms with regard to the painful sensation.
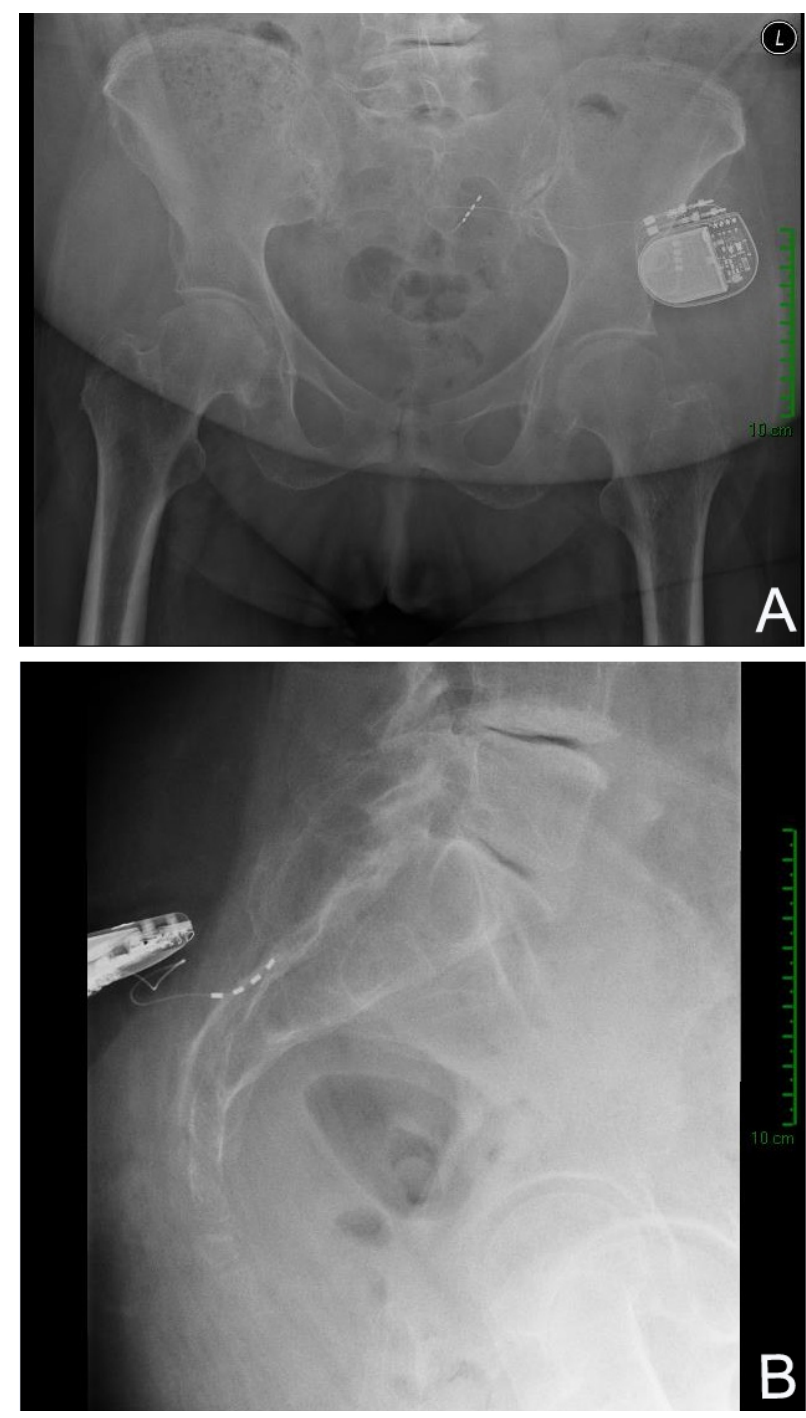

Figure 1. X-ray showing the tined lead posterior to the sacral bone instead of through the third sacral foramen

\section{Discussion}

Since 1995, electric stimulation of sacral nerve roots is applied to produce positive effects in treating pelvic conditions. ${ }^{[5]}$ Although this technique was developed more than 
25 years ago, the exact working mechanism is as yet unclear. Our case is a great testimony to this fact, since a dislodged lead still triggered the right response. These uncertainties leave voids in the technique where further research is needed to refine it.

\subsection{The value of sensory responses}

In the initial test phase (percutaneous nerve evaluation, PNE) as well as when implanting the permanent lead, the lead is positioned in one of the sacral foramina. When a motoric response is observed this constitutes an objective means to confirm contact between an electrode and a nerve. These responses could be contractions of the $\mathrm{m}$. levator ani and/or flexion of the big toe. When the procedure is performed under local anaesthesia this gives the added bonus of patient feedback regarding sensory responses that confirm the correct positioning of the lead and help select the appropriate foramen. ${ }^{[6,7]}$ Isolated sensory responses don't necessarily mean that permanent implantation will fail. Cohen et al. reported that motoric responses are superior to sensory responses in predicting clinical success so they recommend to perform permanent implantation solely when motoric responses were elicited. ${ }^{[8]}$ Yet this is contradicted by data from the study of Govaert et al. which showed that a correct position of the lead can be based on sensory responses alone, illustrating the importance of these sensory responses. ${ }^{[7]}$

\subsection{Foramen selection}

Although there is no known working mechanism, the general principal states that stimulation of a neurologic pathway can modulate an existing effect in another pathway through synaptic interaction. ${ }^{[9]}$ Presumably this results in a change in sacral reflexes, causing stabilisation of contractile activity of the rectum and sphincter as well as an improvement in rectal sensibility. ${ }^{[10]}$ The left or right sacral foramen S3 is the nerve root most frequently chosen when implanting a temporary or permanent lead, since it leads to the best motor responses based on the experience of different research groups. ${ }^{[4,11]}$ This is in accord with the anatomic origin of the innervation of the detrusor muscle and sphincter. Surprisingly S2 and S4 can occasionally elicit the best responses and the area where contact provokes responses indicative of an electrode position in S3 and S4 can vary widely among patients. ${ }^{[4,12]}$

\subsection{Bilateral versus unilateral stimulation}

Although there is experimental and clinical evidence that bilateral stimulation of the sacral nerves can lead to an additive effect, this did not produce significant results in a comparative trial. ${ }^{[13]}$ Hence when unilateral percutaneous nerve stimulation fails, a bilateral test can be contemplated. ${ }^{[14,15]}$

\subsection{Amplitude}

In early articles concerning SNM, the amplitude is set at a level corresponding to the level at which sensory responses were first elicited (the sensory threshold). ${ }^{[16]}$ This is still the most frequently applied tactic. ${ }^{[17]}$ Yet symptom improvement can also be seen in patients who didn't have a sensory response upon implantation which suggests that the amplitude can be set at a level below the sensory threshold without affecting the outcome. ${ }^{[18-20]}$ This reflects the suggestion that the median amplitude necessary to provoke a sensory response is lower in patients with greatest reduction of symptoms. ${ }^{[21]}$

\subsection{Thinking outside the box}

Building on the general principal of neuromodulation through sacral nerve stimulation and supported by cases similar to ours, other techniques have been developed where peripheral nerves are stimulated who connect anatomically to sacral nerves. These techniques are percutaneous tibial nerve stimulation (PTNS) and transcutaneous tibial nerve stimulation (TENS). The posterior tibial nerve finds its roots in the sacral plexus and with PTNS and TENS this nerve is stimulated at the level of the ankle. ${ }^{[22-24]}$ In PTNS a very fine needle is inserted in the tibial nerve posterior to the medial malleolus. An electrical impulse is given through this needle over a period of 30 minutes on a weekly basis. In TENS, stimulation is carried out with self-adhesive stimulation electrodes without the need to insert a needle. Although the results of bigger series have not yet been published, early evidence suggests that these techniques produce the same or similar results as SNM. ${ }^{[25,26]}$

Taking things even further, transcutaneous abdominal electrical stimulation (TEN) seems to elicit improvement of symptoms through unknown pathways with seemingly no anatomic link to the sacral plexus. With this technique a self-adhesive electrode is used on the on the belly and back at the level of the umbilicus. ${ }^{[22-24]}$

\section{Conclusion}

Although the technique of SNM seems to be standardized, this case demonstrates that there are still several steps that need to be clarified in order to define the best way to perform the procedure and then to maximize the outcome.

\section{Key messages:}

- Although the technique seems to be standardized, several steps still need to be clarified in order to define the best way to perform the procedure and then to maximize the outcome.

ISSN 2377-7311 E-ISSN 2377-732X 
- The fact that the lead is still functional despite its dislocated position supports new research in stimulatable peripheral locations with similar results.

- Although already widely applied, it remains unclear how the results of SNM come about.

\section{Ethical approval}

The patient assented to using her medical records and images to publish in this case report.

\section{CONFlicts of InTEREST Disclosure}

The authors declare that they have no conflicts of interest.

\section{REFERENCES}

[1] Leroi AM, Parc Y, Lehur PA, et al. Efficacy of Sacral Nerve Stimulation for Fecal Incontinence. Ann Surg. 2005; 242(5): 662-9. http: //dx.doi.org/10.1097/01.sla.0000186281.09475.db

[2] Vaizey CJ, Kamm MA, Roy AJ, et al. Double-blind crossover study of sacral nerve stimulation for fecal incontinence. Dis Colon Rectum. 2000; 43(3): 298-302. PMid: 10733109. http://dx.doi.org/10. $1007 / \mathrm{BF} 02258292$

[3] Kahlke V, Topic H, Peleikis HG, et al. Sacral Nerve Modulation for Fecal Incontinence. Dis Colon Rectum. 2015; 58(2): 235-40. PMid: 25585083. http://dx.doi.org/10.1097/DCR. 0000000 000000295

[4] Schmidt R, Senn E, Tanagho E. Functional evaluation of sacral nerve root integrity. Urology. 1990; 35: 388-92. http://dx. doi .org/1 $0.1016 / 0090-4295$ (90) 80078-2

[5] Craggs M, McFarlan J. Neuromodulation of the lower urinary tract. Exp Physiol. 1999; 84: 149-60. PMid: 10081715. http: //dx.doi.org/10.1111/j.1469-445X.1999.tb00080.x

[6] Prapasrivorakul S, Gorissen KJ, Gosselink MP, et al. Temporary sacral neuromodulation under local anaesthesia using new anatomical reference points. Tech Coloproctol. 2014; 18(11): 1093-7. PMid: 25151502. http://dx.doi.org/10.1007/s10151-014 $-1207-z$

[7] Govaert B, Melenhorst J, van Gemert W, et al. Can sensory and/or motor reactions during percutaneous nerve evaluation predict outcome of sacral nerve modulation? Dis Colon Rectum. 2009; 52: 1423-6. PMid: 19617755. http://dx.doi.org/10.1007/DCR. 0 b013e3181a91241

[8] Cohen B, Tunuguntla $\mathrm{H}$, Gousse A. Predictors of success for first stage neuromodulation: motor versus sensory response. J Urol. 2006; 175(6): 2178-80. http://dx.doi.org/10.1016/S0022-5 $347(06) 00315-6$

[9] Fall M, Lindström S. Electrical stimulation. A physiologic approach to the treatment of urinary incontinence. Urol Clin North Am. 1991; 18: 393-407. PMid: 2017820.

[10] Fowler C, Swinn M, Goodwin R, et al. Studies of the latency of pelvic floor contraction during peripheral nerve evaluation show that the muscle response is reflexly mediated. J Urol. 2000; 163: 881-3. http://dx.doi.org/10.1016/S0022-5347(05) 67826-3

[11] Melenhorst J, Koch S, Uludag O, et al. Sacral neuromodulation in patients with faecal incontinence: results of the first 100 permanent implantations. Colorectal Dis. 2007; 9: 725-30. PMid: 17509049. http://dx.doi.org/10.1111/j.1463-1318.2007.01241.x

[12] Edlund C, Hellström M, Peeker R, et al. First Scandinavian experience of electrical sacral nerve stimulation in the treatment of the overactive bladder. Scand J Urol Nephrol. 2000; 34: 366-76. PMid: 11195901. http://dx.doi.org/10.1080/003655900455440

[13] Van Kerrebroeck EV, Scheepens W, De Bie R, et al. European experience with bilateral sacral neuromodulation in patients with chronic lower urinary tract dysfunction. Urol Clin North Am. 2005; 32: 517. PMid: 15698876 . http://dx.doi.org/10.1016/j.ucl. 200 4.09.011

[14] Scheepens W, Van Koeveringe G, De Bie R, et al. Long-term efficacy and safety results of the two-stage implantation technique in sacral neuromodulation. BJU Int. 2002; 90: 840-5. PMid: 12460343. http://dx.doi.org/10.1046/j.1464-410X.2002.03028.x

[15] Matzel K, Stadelmaier U, Bittorf B, et al. Bilateral sacral spinal nerve stimulation for fecal incontinence after low anterior resection. Int J Color Dis. 2002; 17: 430-4. PMid: 12355221. http: //dx.doi.org/10.1007/s00384-002-0412-9

[16] Matzel K, Stadelmaier U, Hohenfellner M, et al. Electrical stimulation of sacral spinal nerves for treatment of faecal incontinence. Lancet. 1995; 346: 1124-7. http://dx.doi.org/10.1016/S01 40-6736 (95) 91799-3

[17] Gourcerol G, Gallas S, Michot F, et al. Sacral nerve stimulation in fecal incontinence: are there factors associated with success? Dis Colon Rectum. 2007; 50: 3-12. PMid: 17080278. http://dx.doi.org/10.1007/s10350-006-0746-4

[18] Vaizey C, Kamm M, Roy A, et al. Double-blind crossover study of sacral nerve stimulation for fecal incontinence. Dis Colon Rectum. 2000; 43: 298-302. PMid: 10733109. http://dx.doi .org/10.10 07/BF02258292

[19] Duelund-Jakobsen J, Buntzen S, Lundby L, et al. Sacral nerve stimulation at subsensory threshold does not compromise treatment efficacy: results from a randomized, blinded crossover study. Ann Surg. 2013; 257(2): 219-23. PMid: 23001079. http://dx.doi .org/10 1097/SLA. 0b013e318269d493

[20] Koch S, van Gemert W, Baeten C. Determination of therapeutic threshold in sacral nerve modulation for faecal incontinence. Br J Surg. 2005; 92: 83-7. PMid: 15584063. http://dx.doi .org/10. $1002 /$ bjs .4757

[21] Dudding T, Parés D, Vaizey C, et al. Predictive factors for successful sacral nerve stimulation in the treatment of faecal incontinence: a 10year cohort analysis. Color Dis. 2008; 10: 249-56. PMid: 17655722 http://dx.doi.org/10.1111/j.1463-1318.2007.01319.x

[22] Clarke MCC, Chase JW, Gibb S, et al. Improvement of quality of life in children with slow transit constipation after treatment with transcutaneous electrical stimulation. J Pediatr Surg. 2009; 44(6): 1268-72; discussion 1272. PMid: 19524752. http://dx.doi.org $/ 10.1016 / \mathrm{j}$. jpedsurg. 2009.02.031

[23] Chase J, Robertson VALJ, Southwell B, et al. Pilot study using transcutaneous electrical stimulation ( interferential current) to treat chronic treatment-resistant constipation and soiling in children. J Gastroenterol Hepatol. 2005; 20: 1054-61. PMid: 15955214 http://dx.doi.org/10.1111/j.1440-1746.2005.03863.x

[24] Van Wunnik BPW, Baeten CGMI, Southwell BR. Neuromodulation for constipation: sacral and transcutaneous stimulation. Best Pract Res Clin Gastroenterol. 2011 Feb; 25(1): 181-91. PMid: 21382589 http://dx.doi.org/10.1016/j.bpg.2010.12.008 
[25] Thin N, Taylor S, Bremner S, Emmanuel A, et al. Randomized clinical trial of sacral versus percutaneous tibial nerve stimulation in patients with faecal incontinence. Br J Surg. 2015; 102(4): 349-58. PMid: 25644291. http://dx.doi.org/10.1002/bjs. 9695
[26] Bouguen G, Ropert A, Lainé F, et al. Effects of transcutaneous tibial nerve stimulation on anorectal physiology in fecal incontinence: a double-blind placebo-controlled cross-over evaluation. Neurogastroenterol Motil. 2014; 26(2): 247-54. PMid: 24304363. http://dx.doi.org/10.1111/nmo.12256 